\title{
"That's So Much More Important than the Grades": Learning Client Centered Care through Experiential Learning at Aphasia Camp
}

\author{
Esther S. Kim \\ University of Alberta, esther.kim@ualberta.ca \\ J. Renzo Garcia \\ University of Alberta, jgarcia@ualberta.ca \\ DOI: https://doi.org/10.30707/TLCSD3.2Kim
}

Follow this and additional works at: https://ir.library.illinoisstate.edu/tlcsd

Part of the Communication Sciences and Disorders Commons

\section{Recommended Citation}

Kim, Esther S. and Garcia, J. Renzo (2019) "'That's So Much More Important than the Grades": Learning Client Centered Care through Experiential Learning at Aphasia Camp," Teaching and Learning in Communication Sciences \& Disorders: Vol. 3: Iss. 2, Article 3.

DOI: https://doi.org/10.30707/TLCSD3.2Kim

Available at: https://ir.library.illinoisstate.edu/tlcsd/vol3/iss2/3

This Scholarship of Teaching and Learning Research is brought to you for free and open access by ISU ReD: Research and eData. It has been accepted for inclusion in Teaching and Learning in Communication Sciences \& Disorders by an authorized editor of ISU ReD: Research and eData. For more information, please contact ISUReD@ilstu.edu. 


\title{
"That's So Much More Important than the Grades": Learning Client Centered Care through Experiential Learning at Aphasia Camp
}

\author{
Abstract \\ Interventions aimed at increasing life participation for people with aphasia (PWA), such as camp-based \\ programs, are being increasingly implemented throughout North America. Such camps present a unique \\ experiential learning opportunity for students in speech-language pathology (SLP) programs. The purpose \\ of this study was to examine the impact of participation in aphasia camp on SLP students' acquisition of \\ the skills and attitudes required for client-centered care for PWA. Ten SLP students who volunteered at a \\ weekend-long aphasia camp participated in focus groups examining their learning outcomes following \\ their camp experience. Conventional content analysis was used to analyze the focus group transcripts. \\ Several themes emerged which were categorized into specific learning outcomes and contextual factors \\ that facilitated the learning of these outcomes. Learning outcomes included: 1) students began to think \\ of people with aphasia as more than their disability; 2) students developed more empathetic perspectives \\ of people with aphasia; and 3 ) students improved their skills in supporting communication. Three \\ contextual factors were also identified: 1 ) absence of evaluation; 2) absence of client-clinician power \\ differential; and 3) interdisciplinary environment. These results demonstrate the potential utility of \\ aphasia camps as a medium for learning client-centered care and highlight possible factors that \\ encourage active learning.
}

\section{Keywords}

client-centered care, experiential learning, immersion learning, aphasia camp, speech-language pathology, rehabilitation

\section{Cover Page Footnote}

The authors would like to acknowledge Andrea Ruelling and Karin Werther for their contributions to this project. The Alberta Aphasia Camp is made possibly through a partnership between March of Dimes Canada and the Faculty of Rehabilitation Medicine at the University of Alberta.

This scholarship of teaching and learning research is available in Teaching and Learning in Communication Sciences \& Disorders: https://ir.library.illinoisstate.edu/tlcsd/vol3/iss2/3 
"That's so much more important than the grades": Learning client-centered care through participation in aphasia camp

Clinical speech-language pathology (SLP) programs are designed to train students to become competent and independent clinicians equipped with the knowledge, skills, and attitudes to practice within various contexts. A major aspect of clinical education for SLPs is a focus on client-centered care. Clinical programs are tasked with the challenge of ensuring students learn and incorporate client-centeredness in their clinical practice. In this study, we explored the impact of aphasia camp participation on learning outcomes of pre-professional SLP students. Specifically, we sought to examine how participation in an immersion experience (i.e., aphasia camp) impacts learning of concepts of client-centered care.

Many different types of "centeredness" have been described in the health care literature, including client-, patient-, person-, and family-centeredness. Although there are common themes across each type of centeredness, there are subtle differences and the justification for using one term over another is embedded in practice (Hughes, Bamford, \& May, 2008). For example, "family-centeredness" is appropriate in the context of child health and welfare, whereas "patientcenteredness" is the term often used when focusing on illness and its management. For the purposes of this study, we will use the term "client-centered" care, originally rooted in the work of Carl Rogers (Rogers, 1951). Rogers initially discussed the term in the context of therapeutic relationships. It has since been adopted in other health care fields, resulting in variations in how it is defined (Bosman, Bours, Engels, \& de Witte, 2008; Law, Baptiste, \& Mills, 1995) and implemented in clinical practice (Morgan \& Yoder, 2012). There is, however, one overarching similarity between definitions of client-centered care, which points to a core foundational principle: the meaningful and respectful engagement of clients as partners throughout the process of their care (Kitson, Marshall, Bassett, \& Zeitz, 2013; Morgan \& Yoder, 2012; Sumsion \& Law, 2006).

Another keystone of client-centered care that was pioneered by Rogers is the clinical importance of empathy, which is critical for effective communication between medical professionals and clients (Bauchat, Seropian, \& Jeffries, 2016). He defines it as:

The state of empathy, or being empathic is to perceive the internal frame of reference of another with accuracy and with the emotional components and meanings which pertain thereto as if one were the person, but without ever losing the 'as if' condition. Thus it means to sense the hurt or the pleasure of another as he senses it and to perceive the causes thereof as he 
perceives them, but without ever losing the recognition that it is as if $\mathrm{I}$ were hurt or pleased, etc. (Rogers, 1959, pp. 210).

Empirical studies have also demonstrated the benefit of client-centered care: patients reported increased satisfaction with their care (Wolf, Lehman, Quinlin, Zullo, \& Hoffman, 2008), increased perceived quality of care (Bowers, Fibich, \& Jacobsen, 2001), and clinicians also found improved therapeutic outcomes (Maitland, Fine, \& Tracy, 1985; Sumsion \& Law, 2006). These benefits have made client-centered care attractive to key stakeholders, who have taken steps to advocate for and implement client-centered care in clinical practice. For example, the Life Participation Approach to Aphasia (LPAA)(LPAA Project Group, 2000) represents a consumer-driven philosophy of client-centered care that advocates for a holistic approach to clinical decision-making. The LPAA advocates for focusing on the life concerns of those affected by aphasia (including individuals themselves and their caregivers) when making clinical decisions.

The philosophical orientation of client-centered care runs counter to the principles of the medical model, which has traditionally governed many health professions, including the field of SLP (Luterman, 2008; Ross \& Wertz, 2003). Within the medical model, the focus of the speech-language pathologist is to apply structured therapies in order to address a targeted disorder - the client is not necessarily engaged as an equal in their therapy. DiLollo and Favreau (2010) argue that this model may result in a narrowed view of one's role as a speech-language pathologist. Instead of viewing the role more holistically, one's perceptions of their role may be restricted to that of an expert or teacher of communication. More recently however, the shift away from the traditional medical model is driven in part by an emphasis on incorporating principles of evidence-based practice (EBP) as a component of providing quality clinical care. An EBP approach involves integrating high-quality research evidence with practitioner expertise and client preferences and values when making clinical decisions (American SpeechLanguage-Hearing Association , 2005). Thus, a central objective for SLP students is to learn how to be client-centered in providing clinical care.

\section{Pedagogy in Speech-Language Pathology}

SLP programs have tended to rely on a model of education emphasizing the use of classroom-based lectures and supervisor-directed clinical practicums (Rodger, Webb, Devitt, Gilbert, Wrightson, \& McMeeken., 2008; Ginsberg, Friberg \& Visconti, 2012). Both methods depend on the presence of an educator-expert and involve the transmission of knowledge from the educator-expert to the student. More recently, experts in pedagogy have advocated for SLP students to play a 
more active role in the classroom by moving from a focus on education to learning. The use of these two terms is purposeful: education implies the involvement of an educator, and a transactional relationship between educator and student. On the other hand, the term learning is associated with the changes in knowledge, skills, and attitudes within an individual (Itin, 1999). Barr and Tagg (1995) discuss this change in focus as a paradigm shift from the "Instructional Paradigm" where students are passive receivers of the teacher's knowledge, to the "Learning Paradigm" where students are active co-constructors of knowledge. This type of active learning has been employed with some success in several subfields within SLP, including dysphagia (Goldberg, Richburg, \& Woods, 2006), dementia (Kaf, Barboa, Fisher, \& Snavely, 2011; Mahendra, Fremont, \& Dionne, 2013), and audiology (Serpanos \& Senzer, 2015). These studies focus on the preparation of students for clinical interactions pertaining to each of these subfields. Currently, researchers have yet to examine the impact of active learning approaches on the acquisition of skills necessary for client-centered care.

\section{Teaching and Learning Client-Centered Care}

Dwamena, Holmes-Rovner, Gaulden, Jorgenson, Sadigh, Sikorskii, Lewin, Smith, Coffey, Olomu, and Beasley (2012) investigated the impact of interventions aiming to promote a client-centered approach by front-line service providers. These interventions focused on improving the communication skills of both practicing and pre-professional physicians and nurses by emphasizing the cooperative nature of client-centered decision-making (Alder, Christen, Zemp, \& Bitzer, 2007; Briel, Langewitz, Tschudi, Young, Hugenschmidt, \& Bucher, 2006). The implementation of these interventions typically involved explicit instruction of the principles of client-centered care and opportunities to apply these principles via role-play. Although the authors concluded that these interventions were effective at improving the client-centered communication skills of service providers, there was no discussion of specific interventions that are the most efficient in teaching client-centered care.

Experiential learning paradigms are becoming increasingly popular in university settings (Sheehan, McDonald, \& Spence, 2009), and may be useful as a means of teaching concepts of client-centered care (Brunero, Lamont, \& Coates, 2010; Levine, 2009; Maltby \& Abrams, 2009). Kolb (1984) defined experiential learning as "a process whereby knowledge is created through the transformation of experience" (p. 38). In the classroom, experiential learning activities such as role-plays, simulations, and case studies allow SLP students to integrate and apply content they are learning (Kisfalvi \& Oliver, 2015). Clinical practicums take these activities a step further, but fall short of truly exposing students to the lived 
experience of people who have communication disorders. Immersion experiences are designed to expose students to a broad range of interpersonal experiences and are particularly useful in bridging the gap between the classroom, clinic and in depth understanding of life with a communication disorder. Although immersion learning experiences have been applied extensively in the field of nursing (Levine, 2009; Maltby \& Abrams, 2009; Ryan, Twibell, Brigham, \& Bennett, 2000), to our knowledge only one description of an immersion learning experience specific to the field of speech-language pathology exists (Hoepner, Clark, Sather, \& Knutson, 2012). In their paper, the authors describe the implementation of an immersion experience where undergraduate students engaged people with aphasia (PWA) and their caregivers in meaningful activities in a supported communication environment. They reported several outcomes derived from thematic analysis of content from student artifacts (e.g., essays, discussion posts, daily journals). Students demonstrated a developmental learning sequence, including increased understanding and application of previous knowledge, and commitment to making a meaningful impact as future professionals. Notably, students reported an evolving perspective of individuals with aphasia - namely, the recognition that PWA had much more to them beyond their diagnoses. This holistic view of PWA is a vital component of client-centered practice. Immersion learning experiences such as aphasia camp may be potentially valuable models for pre-professional students in speech-language pathology to learn principles of client-centered care.

\section{The Aphasia Camp Model: Alberta Aphasia Camp}

The Alberta Aphasia Camp (ABAC) is a weekend retreat for people with aphasia (PWA) and their care partners to experience recreational and therapeutic activities in a supportive environment designed to facilitate communication success. LPAA principles are foundational to the design and mission of ABAC. Pre-professional SLP, occupational therapy (OT), and physical therapy (PT) students from the Faculty of Rehabilitation Medicine at the University of Alberta serve as student volunteers for the weekend under the guidance of an interdisciplinary team of professionals.

ABAC provides a unique immersion experience designed for SLP students to learn principles of client-centered care within an active learning framework. Students are responsible for organizing and leading activities during camp, providing communication support for PWA, and facilitating their participation throughout the weekend. Students engage in two face-to-face training sessions prior to camp. These sessions focus on: providing an introduction to the goals of camp, reviewing supported communication techniques (including role-playing of situations that may arise at camp) and reviewing logistics. Students also engage in 
small-group planning forums where they collaborate in planning activities for camp, which they are involved in facilitating throughout the weekend.

\section{Objective}

Although research into outcomes for campers (PWA and caregivers) at the Alberta Aphasia Camp have been reported (Kim, Ruelling, Garcia, \& Kajner, 2017), there has not yet been investigation into the potential outcomes for students from this immersion learning experience. The purpose of this study was to examine the impact of participation in aphasia camp on SLP students' acquisition of the skills and attitudes required for client-centered care for PWA.

\section{METHODS}

Participants. Participants in this study were ten pre-professional students enrolled in the MScSLP (Master's of Science in Speech-Language Pathology) program in the Department of Communication Sciences and Disorders at the University of Alberta. These students comprised 10 of the 26 total student volunteers at $\mathrm{ABAC}$ in 2015. The remaining sixteen volunteers who did not participate were students in the pre-professional physical therapy program (3), occupational therapy program (3), and speech-language pathology program (10). All participants were female and were an average of $25.0(S D=2.2)$ years of age. At the time of their participation in ABAC, all students were in their second year of studies and had completed one in-house clinical practicum placement as well as a course on adult language disorders, which included a workshop on supported communication techniques for aphasia. Students engaged two training sessions where expectations and responsibilities at camp were outlined. In addition, students self-selected into interdisciplinary teams, responsible for planning and implementing activities at camp.

Data Collection and Analysis. Interviews were the main source of data, and group interviews were chosen as the data collection strategy for two main reasons. First, richer responses may be obtained due to agreements or disagreements that can arise between interviewees; and second, data can be gathered more quickly compared to one-on-one interviews (Kitzinger, 1994; Lederman, 1990; Morgan, 1996). Due to the relative paucity of research on this topic, these interviews were semi-structured so that students could voice their opinions without being overly constrained by a set of questions. A topic guide was used when students were exhibiting difficulty with generating ideas and discussion. The guide included topics such as roles and responsibilities at camp and working in interdisciplinary teams. Participants were asked open-ended questions regarding their learning at 
ABAC such as "Can you tell me about the most meaningful experience you had at aphasia camp?" (see Appendix A for a topic guide and list of questions).

Group interviews were conducted by the second author (RG), who was a student in the first year of the MScSLP program at the time of the interviews. The study participants knew him as a member of another cohort but he was not involved in volunteering at ABAC. He had completed coursework on qualitative methods and a workshop on facilitating interviews, and had previous experience as a research assistant participating in focus group interviews. In total, three group interviews were conducted approximately one month following camp: one group involved four students and the other two involved three students each. Each group interview was approximately 45 minutes and was audio-recorded and transcribed verbatim. Member checking was conducted during the interview process by having the interviewer summarize, verify, and request clarification of interviewee statements.

The data was analyzed by both authors using conventional content analysis (Hsieh $\&$ Shannon, 2005). To begin the analysis, interview transcripts were reviewed at least two times in order to become immersed in the data (Tesch, 1990). Then, open coding was performed, where descriptive labels are used to summarize portions of the data. This was an iterative process where codes were generated until saturation was achieved. These codes were then grouped into emergent categories that demonstrated the relationship between a given set of codes. Definitions based on the content of each code/category were developed. Although data analysis was conducted using an inductive approach, sensitizing concepts (Charmaz, 2014) brought to the process stemmed from the authors' philosophy of teaching and learning, and the framework upon which the Alberta Aphasia Camp was created. Specifically, these included interdisciplinarity, active learning, and the core values of the LPAA philosophy.

\section{RESULTS}

Analysis of the interview transcripts revealed codes that were organized into two broad categories. The first category represented learning outcomes that students identified were a direct result of their participation as volunteers at ABAC. These included: 1) a recognition that PWA are more than their deficit by thinking beyond the disability; 2) development of more empathic perspectives towards PWA; and 3) consolidation of their supported communication skills. The second category represented important factors that facilitated student learning at ABAC: 1) absence of evaluative pressure; 2) absence of the clinician-client power differential; and 3) being in an interdisciplinary environment. These concepts are 
depicted visually in Figure 1. Note, our use of the term "learning outcomes" in the context of this study refers to the outcomes generated by the students as a result of participating in the camp, as opposed to the traditional usage of the term to reflect outcomes that would be imposed on students.

\section{Learning Outcomes}

\begin{tabular}{|c|c|c|}
\hline $\begin{array}{c}\text { Thinking beyond } \\
\text { disability }\end{array}$ & $\begin{array}{c}\text { Developing } \\
\text { empathy }\end{array}$ & $\begin{array}{c}\text { Supporting } \\
\text { communication }\end{array}$ \\
\hline
\end{tabular}

\section{Environmental Factors}

\begin{tabular}{|c|c|c|}
\hline $\begin{array}{c}\text { Absence of } \\
\text { evaluation }\end{array}$ & $\begin{array}{c}\text { Absence of power } \\
\text { differential }\end{array}$ & $\begin{array}{c}\text { Interdisciplinary } \\
\text { environment }\end{array}$ \\
\hline
\end{tabular}

Figure 1. Learning outcomes and environmental factors contributing to learning outcomes observed in pre-professional SLP students following participation in the Alberta Aphasia Camp

\section{Learning Outcomes.}

Thinking beyond disability. This theme focuses on the students' recognition that the lives and identities of PWA extend beyond their impairment. Although students mentioned that they received training in the provision of client-centered care over the course of their degrees, some were surprised at how much more they learned about PWA with whom they had interacted previously. This notion is reflected in one student's recounting of her experience at camp:

"My client [from summer clinic] was at aphasia camp and he was part of my conversation group. I had him all summer, and we formed a relationship, we had good banter back and forth, and he's a great guy, and I was super stoked he came to camp. At camp, I thought, 'Wow, I learned so much more about you as a person. Not just your ability or disability, what have you. I learned not just about the type of severity of aphasia, I learned about how that actually hits your life."”

Another student expressed difficulty with learning more about her client's life in a clinical context, despite implementing what she learned about client-centered care: 
"I did a quality of life scale, you know, and arguably, I asked questions that were supposed to get at other aspects of my client's life. But I feel like until aphasia camp, I didn't get at anything actually outside of the specific type/severity of aphasia kind of thing... [it] was very impairment focused"

The most common sentiment shared among students was a reinforced understanding of a PWA's life roles beyond that of a person with aphasia:

"[The conversation groups] let me see beyond [PWA] being here at camp. They are dads or moms at home, and they do have other roles and responsibilities besides having a weekend off here. Kind of just put things into perspective."

Developing empathy. In this second theme, the emphasis is on the development of the students' ability to empathize with PWA. Students strived to share the experiences of PWA with the keen recognition of their limitations in their ability to completely understand what it is like to live with aphasia since they themselves do not live with the disorder (i.e., continuing to meet the "as if" condition in Rogers' (1959) definition). In doing so, students have surpassed sympathy and have developed a more empathic perspective:

"... one other gentleman turned to me, and he was like, 'No offense, but you guys don't get it. You're very nice, but you don't get it.' And it's like, you know what? We don't get it. We can very much try and put ourselves in their place and try and understand them, but it's very important that they have these spaces where they can support each other because they've been through something similar that no one else really gets."

Although the students' reflections during the interview are congruent with Rogers' (1959) definition of empathy, there seemed to be some confusion with terminology that may have lead some students to believe that they were not expressing empathy:

"ABAC facilitated true and genuine empathy. Like we can sort of... maybe I'm not getting this right - sympathize versus empathize-I think we can sympathize and say, 'I can imagine how you might feel' but unless we've experienced it or unless we've been a caregiver and we've had to go through this giant switch, we can't say what that's like."

Supporting communication. The final theme pertains to the application and consolidation of the knowledge and skills required for supporting communication. For SLP students, ABAC allowed them to practice, improve, and adapt their supported communication skills for each person they communicated with: 
“...it was kind of tricky at times because you would first approach a person with aphasia and you weren't sure what level of language they have. So could they speak verbally? Could they just nod yes or no? Did you have to use written communication? So you kind of figured that out through interacting with them. The interactions looked different for each person."

Students identified that their experience at ABAC allowed them to practice and consolidate the skills they learned in the supported communication workshop in their aphasia class:

"I think I've learned the value of patience when you're interacting with individuals with aphasia. It's so tempting to just jump the gun and say what you know they want to say. I've definitely learned by watching [other students] the value and importance of patience and letting someone finish their thoughts without jumping in and cutting them off."

\section{Environmental Factors.}

Absence of evaluation. The absence of evaluation at ABAC was the most common and most explicit factor identified by the students as helpful for their learning. Students compared their experience at ABAC to their clinical and classroom education and verbalized the utility of the freedom that ABAC afforded them with regards to being able to learn at their own pace:

"...in clinic, you figured out based on the specific tests that you run, rather than just sitting down and having a conversation and going, 'Oh now I'm recognizing, or I'm picking up on the fact that this is helpful for you, or this isn't helpful for you, or you don't need it.' So you figure out what supports they need naturally without any sort of pressure of 'Is this right or wrong? Is there any sort of timeline to it? Am I getting graded for it?' That kind of thing."

Absence of power differential. This pertains to the absence of the power differential that is inherent in a clinician-client relationship where the clinician is in the more privileged position. At ABAC, students did not think in terms of this clinician-client relationship, with one student saying, "You know, you're not thinking this is the weekend to work on therapy, like, this isn't the weekend to work on their goals". Instead, students reconceived their roles as facilitators of camper-to-camper connections so that PWA can help each other:

"I think the important thing to remember is that, the weekend was about [PWA], it wasn't about us. (other students: Mmhm.) It was about them connecting to each other and we were there to help facilitate that." 
Another student clarified her conception of her role at ABAC:

"I didn't feel like we were being 'student clinicians' or anything like that. You're connecting with them on a basic human being level. It's a good way of putting it. I don't know how else to put that."

Interdisciplinary environment. This third and final factor involves the exchange of information and skill-building between students of different disciplines. Students recognized they all had differing expertise and appreciated learning about other aspects of aphasia beyond the communication impairment. In addition, SLP students expressed that they felt grateful for the support that OT and PT students could offer with regards to the physical needs of campers:

"...some people with aphasia also have motor, physical or other issues because they'll have hemiparesis or they'll have other things so we should be working together [with PT and OT]."

Students agreed that interdisciplinary teams are the best way to ensure that a camper's needs are being met: "We can't work alone anymore. We are not separate disciplines, we need to make best of a situation and make sure that the client gets the best resources they can." They also recognized the exposure to working on an interdisciplinary team that they garnered from their experience at $\mathrm{ABAC}$ could be applied to their future careers, and expressed the desire to have additional, authentic experiences working with PT and OT students.

\section{DISCUSSION}

The present study sought to identify the learning outcomes of SLP student volunteers who participated in an experiential learning opportunity at the Alberta Aphasia Camp, and the environmental factors that facilitated these outcomes. Three primary learning outcomes emerged: students are thinking beyond a client's disability, demonstrating empathic development, and improving their ability to support communication. These outcomes are precipitated by three factors: the absence of evaluative pressure, the absence of the client-clinician power differential, and being in an interdisciplinary environment.

The three themes labeled as learning outcomes all indicate movement towards proficiency in the skills necessary for client-centered care. The outcomes of thinking beyond a client's disability and developing empathy allow students to see their clients more holistically. In order to provide client-centered care, students must be able to take factors beyond a person's disability into account during clinical encounters (Epstein, 2000). For example, being attentive to a client's sociocultural background could allow a student clinician to tailor therapy 
activities to both a client's needs as well as their preferences. It is by integrating clinical knowledge with client perspectives that a student clinician can be responsive to the needs of their clients.

The outcome of improved supported communication may not seem immediately relevant to the provision of client-centered care. However, the link between communication and client-centered care is evident in research. The focus of several interventions for providers to be more client-centered is on improving communicative interaction skills (e.g., Briel et al., 2006; Heaven, Clegg, \& Maguire, 2006; Razavi, Merckaert, Marchal, Libert, Conradt, Boniver, Etienne, Fontaine, Janne, Klastersky, \& Reynaert., 2003; see the review by Dwamena et al., 2012 for a list of similar studies). For PWA, their difficulty with language could exacerbate the interactional requirements for client-centered care, which makes supported conversation a necessity for revealing their competence.

The three environmental factors identified as facilitative for student learning are factors that may not be present in traditional learning contexts, such as the classroom or the clinic. The most markedly different factor that separates the learning environments of the classroom and clinic from ABAC is the absence of evaluation. Students were able to learn more freely, without the pressure of what to learn, how to learn it, and in what timeframe the learning must take place. This freedom allows students to practice active learning, which promotes reflective thinking and critical questioning (Ginsberg, Friberg, \& Visconti, 2012; Goldberg, Richburg, \& Wood, 2006). Furthermore, this environment shifts the focus from studying for a test, to developing one's clinical identity. As one student succinctly notes:

'It's just like, 'Do I care about getting 90\% on this exam?' No, because you know what your job is going to look like, and will anyone care what kind of grade you got in child language? No. Will they care about how you interact with your clients? Are you a kind and gentle person? Do you provide empathy? Are you a listening ear? That's so much more important than the grades."

The second factor, absence of a power differential is related to the previous factor and supports the three identified learning outcomes. In the classroom, there exists the possibility for a power imbalance between students and teacher. A similar imbalance could be present in the clinic room, between the clinical educator and the student clinician, as well as between the student clinician and the client. However, students at ABAC felt that they were able to free themselves of the "student clinician" label and "connect with [the campers] on a more human, equal level". In doing so, students were able to have the meaningful interactions that 
allowed for them to see more than a person's disability and to develop strong empathic bonds. Throughout these interactions, students also practiced their supported communication skills in a more naturalistic setting.

The third factor of interdisciplinarity was useful for students in understanding their roles on interdisciplinary teams, and working collaboratively towards the common goal of ensuring people with aphasia were able to fully participate in recreational and therapeutic activities in a supported environment. SLP students discussed how they understood better the role of OTs and PTs by observing their peers throughout the weekend. They also discussed how learning about aspects of PWA outside of the discipline of SLP (e.g., considerations for interacting with an individual with hemiparesis) helped them to have a more holistic view of clients with aphasia. Several students affirmed they believed this experience would serve them well when interacting on interdisciplinary teams in the future. Interestingly, several SLP students noted that the "real world" interdisciplinary experience at $\mathrm{ABAC}$ was more beneficial than a semester-long interdisciplinary course they took, where students from various health disciplines worked together on simulations and case studies: "I learned more about the other disciplines in that one weekend than I did in that one whole course just because you... it's such a real-life application".

Finally, it is worth noting that ABAC was set up intentionally using an LPAAbased framework. That is, the emphasis of the camp was on fostering social connections amongst people affected by aphasia, and providing opportunities therapeutic and recreational activities in an accessible, supported environment. By design, this framework likely contributed to the client-centered learning outcomes as identified by students.

\section{Limitations and Future Directions}

One limitation of the present study is that one month had passed between the end of camp and when the interviews were conducted. Although there is the potential for recall bias, we chose to wait to conduct interviews as we felt students had some time to reflect and process what they had experience. Another limitation is the relative contribution of each of the environmental factors in creating a supportive learning environment is unknown. Any one or any combination of these factors could be the keystone, but precise determination thereof necessitates further investigation. Another area for future research is whether students who have reported these learning outcomes are able to draw on this experience to provide more client-centered care in clinical settings. Since the goal of learning experiences such as Alberta Aphasia Camp are to produce clinicians who will 
provide client-centered care, studies examining a student's ability to apply their knowledge would be appropriate. Finally, an examination of acquisition of interdisciplinary competencies by including perspectives of OT and PT students would be beneficial.

Although the results of this study are context-bound, it is possible that the identified environmental factors may be applied to traditional learning settings to encourage active and reflective learning. For example, classroom activities in which students can engage in interactions with people who have communication disorders (e.g., bringing in PWA as speakers/panelists for class discussions) could help reduce the client-clinician power differential. In the clinic room, students could be given more opportunities to interact with their client without explicit supervision to lessen the feeling of being evaluated. In such cases, the method of measuring progress could be through guided self-reflection.

Client-centered care is a complex and multi-faceted construct that has the biopsychosocial needs of an individual at its core. Ultimately, client-centered care can be achieved through respectful shared decision-making, which requires that a clinician be communicative and holistic in their approaches to service delivery. The results of this study demonstrate that an aphasia camp model as described within this paper can have merit in providing a facilitative environment for student clinicians to acquire and practice some of the knowledge, skills, and attitudes required for provision of client-centered care to adults with aphasia. 


\section{References}

Alder, J., Christen, R., Zemp, E., \& Bitzer, J. (2007). Communication skills training in obstetrics and gynaecology: Whom should we train? A randomized controlled trial. Archives of Gynecology and Obstetrics, 276(6), 605-612.

American Speech-Language-Hearing Association. (2005). Evidence-based practice in communication disorders [Webpage]. Retrieved from https://www.asha.org/policy/ps2005-00221/.

Barr, R. B., \& Tagg, J. (1995). From teaching to learning: A new paradigm for undergraduate education. Change Magazine, 27(6), 13-25.

Bauchat, J. R., Seropian, M., \& Jeffries, P. R. (2016). Communication and empathy in the patient-centered care model - Why simulation-based training is not optional. Clinical Simulation in Nursing, 12(8), 356-359.

Bosman, R., Bours, G. J. J. W., Engels, J., \& de Witte, L. P. (2008). Clientcentered care perceived by clients of two Dutch agencies: A questionnaire survey. International Journal of Nursing Studies, 45, 518-525.

Bowers, B. J., Fibich, B., \& Jacobsen, N. (2001). Care-as-service, care-as-relating, care-as-comfort: Understanding nursing home residents' definitions of quality. Gerontologist, 41, 539-535.

Briel, M., Langewitz, W., Tschudi, P., Young, J., Hugenschmidt, C., \& Bucher, H. C. (2006). Communication training and antibiotic use in acute respiratory tract infections: A cluster randomized controlled trial in general practice. Swiss Medical Weekly, 136, 241-247.

Brunero, S., Lamont, S., \& Coates, M. (2010). A review of empathy education in nursing. Nursing Inquiry, 17, 65-74.

Charmaz, K. (2014). Constructing grounded theory. London, UK: Sage.

DiLollo, A., \& Favreau, C. (2010). Person-centered care and speech and language therapy. Seminars in Speech and Language, 31, 90-97.

Dwamena, F., Holmes-Rovner, M., Gaulden, C. M., Jorgenson, S., Sadigh, G., Sikorskii, A.,Lewin, S., Smith, R. C., Coffey, J., Olomu, A., \& Beasley, M. (2012). Interventions for providers to promote a patient-centered approach in clinical consultations. Cochrane Database for Systematic Reviews, 2012(12), 1-178.

Epstein, R. M. (2000). The impact of patient-centered care on outcomes. The Journal of Family Practice, 49(9), 805-807.

Ginsberg, S. M., Friberg, J. C., \& Visconti, C. F. (2012). Scholarship of teaching and learning in speech-language pathology and audiology: Evidencebased education. San Diego, CA: Plural Publishing.

Goldberg, L. R., Richburg, C. M., \& Wood, L. A. (2006). Active learning through service learning. Communication Disorders Quarterly, 27(3), 131-145. 
Heaven, C., Clegg, J., \& Maguire, P. (2006). Transfer of communication skills training from workshop to workplace: The impact of clinical supervision. Patient Education and Counseling, 60, 313-325.

Hoepner, J. K., Clark, M. B., Sather, T., \& Knutson, M. (2012). Immersion learning at aphasia camp. EBE Briefs: Evidence Based Education, September, 1-10.

Hsieh, H. F., \& Shannon, S. E. (2005). Three approaches to qualitative content analysis. Qualitative Health Research, 15(9), 1277-1288.

Hughes, J. C., Bamford, C., \& May, C. (2008). Types of centredness in health care: themes and concepts. Medicine, Health Care and Philosophy, 11(4), 455-463.

Itin, C. M. (1999). Reasserting the philosophy of experiential education as a vehicle for change in the $21^{\text {st }}$ century. The Journal of Experiential Education, 22(2), 91-98.

Kaf, W. A., Barboa, L. S., Fisher, B. J., \& Snavely, L. A. (2011). Effect of interdisciplinary service learning experience for audiology and speech language pathology students working with adults with dementia. American Journal of Audiology, 20, S241-S249.

Kim, E. S., Ruelling, A., Garcia, J. R. \& Kajner, R. (2017). A pilot study examining the impact of aphasia camp participation on quality of life for people with aphasia. Topics in Stroke Rehabilitation, 24(2), 107-113.

Kisfalvi, V. \& Oliver, D. (2015). Creating and maintaining a safe space in experiential learning. Journal of Management Education, 39(6), 713-740.

Kitson, A., Marshall, A., Bassett, K. \& Zeitz, K. (2013). What are the core elements of patient-centered care? A narrative review and synthesis of the literature from health policy, medicine and nursing. Journal of Advanced Nursing, 69(1), 4-15.

Kitzinger, J. (1994). The methodology of focus groups: The importance of interaction between research participants. Sociology of Health \& Illness, 16(1), 103-121.

Kolb, D. (1984). Experiential learning as the science of learning and development. Englewood, NJ: Prentice Hall.

Law, M., Baptiste, S., \& Mills, J. (1995). Client-centered practice: What does it mean and does it make a difference? Canadian Journal of Occupational Therapy, 62(5), 250-257.

Lederman, L. C. (1990). Assessing education effectiveness: The focus group interview as a technique for data collection. Communication Education, 38, 117-127.

Levine, M. (2009). Transforming experiences: Nursing education and international immersion programs. Journal of Professional Nursing, 25(3), 156-169. 
Life Participation Approach to Aphasia Project Group. (2000). Life participation approach to aphasia: A statement of values for the future. In Chapey, R. (Ed.), Language intervention strategies in aphasia and related neurogenic communication disorders $\left(4^{\text {th }}\right.$ ed.)(pp. 23-245). Baltimore, MD: Lippincott, Williams \& Wilkins.

Luterman, D. M. (2008). Counseling persons with communication disorders and their families (5th ed.). Austin, TX: Pro-Ed.

Mahendra, N., Fremont, K., \& Dionne, E. (2013). Teaching future providers about dementia:The impact of service learning. Seminars in Speech and Language, 34(1), 5-17.

Maitland, R. E., Fine, M. J., \& Tracy, D. B. (1985). The effects of an interpersonally based problem-solving process on consultation outcomes. Journal of School Psychology, 23, 337-345.

Maltby, H. J., \& Abrams, S. (2009). Seeing with new eyes: The meaning of an immersion experience in Bangladesh for undergraduate senior nursing students. International Journal of Nursing Education Scholarship, 6(1).

Morgan, D. L. (1996). Focus groups. Annual Review of Sociology, 22, 129-152.

Morgan, S., \& Yoder, L. H. (2012). A concept analysis of person-centered care. Journal of Holistic Nursing, 30(1), 6-15.

Razavi, D., Merckaert, I., Marchal, S., Libert, Y., Conradt, S., Boniver, J., Etienne, A.M., Fontaine, O., Janne, P., Klastersky, J. and Reynaert, C., 2003. How to optimize physicians' communication skills in cancer care: results of a randomized study assessing the usefulness of posttraining consolidation workshops. Journal of Clinical Oncology, 21(16), 3141-3149.

Rodger, S., Webb, G., Devitt, L., Gilbert, J., Wrightson, P., \& McMeeken, J. (2008). Clinical education and practice placements in the allied health professions: An international perspective. Journal of Allied Health, 37(1), 53-62.

Rogers, C. R. (1951). Client-centered therapy: Its current practice, implications, and theory. Boston, MA: Houghton Mifflin.

Rogers, C. R. (1959). A theory of therapy, personality and interpersonal relationships as developed in the client-centered framework. In S. Koch (Ed.), Psychology: a study of a science (Vol. 3):Formulations of the person and the social context (pp. 184-256). New York: McGraw Hill.

Ross, K., \& Wertz, R. (2003). Quality of life with and without aphasia. Aphasiology, 17(4), 355-364.

Ryan, M., Twibell, R., Brigham, C., \& Bennett, P. (2000). Learning to care for clients in their world, not mine. Journal of Nursing Education, 39(9), 401408. 
Serpanos, Y. C. \& Senzer, D. (2015). Experiential instruction in graduate-level preparation of speech-language pathology students in outer and middle ear screening. American Journal of Speech-Language Pathology, 24, 81-87.

Sheehan, B. J., McDonald, M. A., \& Spence, K. K. (2009). Developing students' emotional competency using the classroom-as-organization approach. Journal of Management Education, 33(1), 77-98.

Sumsion, T., \& Law, M. (2006). A review of evidence on the conceptual elements informing client-centered practice. Canadian Journal of Occupational Therapy, 73(3), 153-162.

Tesch, R. (1990). Qualitative research: Analysis types and software tools. New York, NY: Falmer.

Wolf, D. M., Lehman, L., Quinlin, R., Zullo, T., \& Hoffman, L. (2008). Effect of patient-centered care on patient satisfaction and quality of care. Journal of Nursing Care Quality, 23, 316-321. 


\section{APPENDIX A Guiding Questions for Interview}

1. I know it's been a few weeks since Aphasia Camp happened, to get us into the mindset of what happened at camp could you tell me about what you did over the weekend - what were your roles and responsibilities?

a. In what capacity did you support the campers?

2. (if applicable) How was your experience working with people with aphasia at Aphasia Camp similar of different from your experiences working with people with aphasias in clinic?

a. (if applicable) Has your experience at Aphasia Camp shaped how you interact with clients with aphasia now in clinic?

3. What was your experience working with the PT and OT students?

4. What was your most meaningful experience from Aphasia Camp?

5. What were the challenges that you faced at Aphasia Camp and what did you do if anything, to overcome these challenges? 